\title{
Ao vivo em Vai Que Cola
}

\author{
Ana Márcia Andrade \\ Mestranda em Comunicação \\ Audiovisual na PPGCOM da Anhembi \\ Morumbi e integrante do grupo de \\ pesquisa Inovações e Rupturas na \\ Ficção Televisiva Brasileira, certificado \\ pela Universidade Anhembi Morumbi, \\ registrado no CNPQ e integrante do \\ OBITEL.
}

Email: anacherulli@gmail.com
Resumo: A primeira temporada de Vai Que Cola (MULTISHOW, 2013-2015) pode ter produzido efeito singular no espectador televisivo. A simulação da transmissão ao vivo, junto da quebra da quarta parede, a exposição dos bastidores, a reação da plateia e o palco giratório, pode ter proporcionado ao telespectador a sensação de sair do sofá, sentar na plateia do teatro, subir no palco de Vai Que Cola e ainda atravessar as cortinas da sitcom. Com base no conceito da técnica do real sobre a transmissão direta (ao vivo) de Mario Carlón e do conceito de ao vivo de Arlindo Machado, pretende-se identificar por meio da análise audiovisual a contribuição do teatro para a simulação do ao vivo, além de levantar um possível efeito do produto sobre seu público.

Palavras-chave: Ficção televisiva brasileira; Simulação de ao vivo; Sitcom; Teatro; Quebra da quarta parede.

\section{Title: Live in Vai Que Cola}

Abstract: The first season of Vai Que Cola (MULTISHOW, 2013-2015) may have produced a singular effect in the television viewer. The simulation of the live broadcast, along with the breaking of the fourth wall, the exposure of the backstage, the reaction of the audience, and the revolving stage, could have provided the viewer with the feeling of leaving the couch, sitting in the theater audience, going on Vai Que Cola's stage, and also getting behind the curtains of the sitcom. Based on Mario Carlón's concept of the real on direct transmission (live) technique, and Arlindo Machado's live broadcast concept, we intend to identify by audiovisual analysis the theater contribution to the simulation of live and to evaluate a possible effect of the sitcom on its public.

Keywords: Brazilian television fiction; Live broadcast simulation; Sitcom; Theater; Breaking the fourth wall. 
${ }^{1} \mathrm{~A}$ inauguração oficial só aconteceu em setembro de 1950 .

\section{Introdução}

A TV Tupi, em 4 de julho de 1950, às 22 horas, transmitia ao vivo a primeira imagem televisionada para o público brasileiro: os hinos religiosos cantados pelo frei mexicano José Francisco de Guadapule Mojica (SILVA, 1981, p. 10) ${ }^{1}$.
20 termo "transmissão direta" é utilizado neste artigo como sinônimo de "transmissão ao vivo".
A partir da televisão, o registro do espetáculo que se está ainda enunciando e a visualização/audição do resultado final podem se dar simultaneamente e é esse justamente o traço distintivo da transmissão direta: a recepção, por parte de espectadores situados em lugares muito distantes, de eventos que estão acontecendo nesse mesmo instante (na verdade não é exatamente o mesmo instante, pois há um ligeiro atraso entre captação, transmissão e recepção, devido ao percurso do sinal nos canais eletrônicos, mas essa diferença é mínima e pode ser ignorada em termos práticos). (MACHADO, 2003, p. 125, grifo do autor).

Foi contando com essa recepção da transmissão direta² que a TV Tupi transmitiu, depois de dois meses de ensaio, o primeiro teleteatro brasileiro, em novembro de 1950, que se chamava $A$ vida por um fio (SILVA, 1981, p. 10). Já em 1960, não mais com as mesmas restrições tecnológicas e mais longe da imprevisibilidade da transmissão direta, a TV Tupi levou ao ar Hamlet, uma adaptação de Shakespeare: o primeiro teleteatro gravado em VT no Brasil (MATTOS, 1990, p. 66).

Um grande passo foi dado desde a transmissão mencionada no primeiro parágrafo deste artigo até o uso do videotape. Entretanto, para Arlindo Machado (2003, p. 126), mesmo os programas pré-gravados incorporam "em sua matéria uma boa parte dos traços da transmissão ao vivo". Por "comodidade técnica ou questões econômicas e institucionais", eles são "produzidos e editados nas mesmas circunstâncias que os programas ao vivo (portanto, em tempo presente), ou em condições muito próximas a ele" (loc. cit., grifo do autor).

\begin{abstract}
Embora a transmissão direta propriamente dita seja uma experiência fenomenológica específica, imprevisível e irrepetível, o seu registro em fita magnética ainda guarda parte das marcas de incompletude e de intervenção do acaso, impossíveis de encontrar em trabalhos realizados em outras situações produtivas. No limite, até mesmo seriados e novelas, em que as convenções narrativas de certa forma impõem pelo menos um rascunho de decupagem e montagem, não estão inteiramente livres da influência do tempo presente (loc. cit., grifo meu).
\end{abstract}

É nesse limite citado por Machado que se destaca a sitcom Vai Que Cola (20132015), do canal de TV a cabo Multishow. A sitcom traz características do teleteatro do início da televisão, seja em transmissão direta ou previamente gravado. O teatro do HSBC Arena, no Rio de Janeiro, foi o palco que comportou o cenário giratório na primeira temporada de Vai Que Cola. A temporada foi exibida de 8 de julho a 30 de agosto de 2013 , de segunda a sexta-feira, com programas gravados antes da exibição. Segundo o canal, é a "atração de maior audiência da TV paga nos últimos 10 anos. Os primeiros 20 episódios reuniram 11 milhões de espectadores" (MULTISHOW, 2013).

A segunda temporada estreou com um único episódio ao vivo no dia 1 10 de setembro de 2014, e permaneceu até 24 de outubro de 2014, com episódios gravados ainda no HSBC Arena. A terceira temporada, gravada no Riocentro, também na Barra da Tijuca, teve sua estreia dia 19 de outubro de 2015 e não foi finalizada até a data do fechamento deste texto.

O enredo da sitcom se passa no subúrbio do Rio de Janeiro, no bairro do Méier, e todos os episódios acontecem na pensão de Dona Jô. Tudo começou no dia em que 
o golpista Valdomiro Pinto, Valdo, interpretado por Paulo Gustavo, se escondeu na pensão para fugir da polícia. Essa foi a deixa para a criação dos enredos diários, que geralmente trazem uma frustrada tentativa de golpe e ascensão social por parte de um dos personagens. Dona Jô (interpretada por Catarina Abdala) aceita abrigar Valdo com a condição de que ele passe a ter uma vida honesta, sem tentativas de golpes. Porém, isso nunca acontece.

A maioria dos estratagemas do ao vivo utilizados na sitcom parece construída no formato teatral. Gravada a partir da atuação dos atores em um palco giratório com direito a plateia, as câmeras televisivas geram um formato pouco utilizado: captam o teatro, com seus improvisos e erros já previstos no roteiro ou não. Esse conjunto híbrido (teatro e TV) trabalha a favor de uma receptividade específica do telespectador (discutida à frente) diante de uma obra de ficção produzida após a criação do VT.

Atrelados ao enredo e às personagens estão, no formato híbrido, situações e momentos característicos da transmissão ao vivo. Assim, dá-se ao telespectador a impressão de que a captação das imagens e sons da sitcom é feita no mesmo momento em que se assiste ao produto televisivo. Portanto, ocorrem situações de improvisação, momentos de exibição de erros e exposição de bastidores. Em relação à última ocorrência, pode-se observar o aparato de iluminação, câmeras, plateia, cenário e até mesmo a orientação da direção. A maioria desses elementos, geralmente, leva ao distanciamento do ilusionismo, do naturalismo e, consequentemente, à quebra da quarta parede, expressão que será definida adiante.

O objetivo deste artigo é buscar possíveis respostas às perguntas: a) seria possível detectar um propósito específico para a utilização da simulação do ao vivo nessa narrativa?; b) onde está a contribuição da técnica teatral?; e c) qual a relevância dessa técnica para a recepção do seu público?

Cada tentativa de aproximação a um fenômeno discursivo realizada hoje apresenta uma complexidade tão grande que nossas categorias analíticas, formadas no estudo de campos estáticos e prévios a esta extraordinária transformação, tendem a revelar-se insuficientes se não forem, no mínimo, articuladas com algo mais. E se esse é o estado atual, entendo que cabe perguntar: isso se deve a que imediatamente todos - os comunicadores, os artistas, os políticos, os pregadores etc. - tornaram-se gênios criadores, capazes de gerar discursos mais complexos e menos previsíveis? Ou, antes será que a emergência deste novo sistema devido ao surpreendente hibridismo que possibilita, determinou a expansão das possibilidades produtivas - e tanta facilidade para gerar discursos - que finalmente terminaram por alterar profundamente, em todos os níveis, a circulação discursiva e a vida social? (CARLÓN, 2012, p. 13-14).

A complexidade das estratégias de linguagem audiovisual utilizadas em Vai Que Cola parece ser resultado de um hibridismo composto de antigas e novas possibilidades produtivas na circulação discursiva. Consciente de que se possa estar aqui diante de uma possível categoria analítica de aproximação insuficiente do fenômeno discursivo atual, enumerada por Carlón, tenta-se, portanto, se aproximar com humildes passos de uma análise do discurso do "tempo presente" (MACHADO, 2003), tendo como objeto de análise o episódio 31, "Por água abaixo" (MULTISHOW, 2013), da 1a temporada, considerando "seu vínculo com o real e a temporalidade" (CARLÓN, 2012, p. 14).

\section{A quarta parede}

Para entender melhor os recursos de distanciamento utilizados na sitcom, é necessário retomar os significados dos conceitos de ilusionismo, naturalismo, realismo e quebra da quarta parede utilizados no decorrer da história do teatro. 
${ }^{3}$ Em nota desse mesmo livro de Diderot (2005, p. 79), Frank de Mattos afirma: "Diderot é o primeiro a sugerir esta ideia de 'quarta parede', que, até nossos dias, é fundamental para a definição do teatro ilusionista".
Denis Diderot (2005) afirmava que, seja compondo ou representando, não se deve pensar no espectador ${ }^{3}$. $O$ ator deve representar como se a cortina não subisse. Para demonstrar a não interação do personagem com a plateia, Diderot diz que se $o$ ator fizesse bem seu papel:

A plateia diria ao personagem: "Que queres? Não estou aqui. Por acaso intrometo em tua vida? Vai para casa"; e o autor, se fizesse o seu, deixaria os bastidores e responderia à platéia: "Perdão, senhores, a culpa é minha; na próxima vez farei melhor, e ele também” (DIDEROT, 2005, p. 79).

As palavras de Diderot enfatizam que a plateia dialoga diretamente com o autor e não com o ator. Segundo Patrice Pavis (2007, p. 316), no teatro a exigência de separação entre palco e plateia é levada ao extremo pelo realismo e pelo naturalismo. O quadro da representação ilusionista é fornecido quando o espaço cênico é construído com exatidão e respeito à realidade significada.

Para o público, esse quadro parece "transplantado" de sua própria realidade para o palco. [...] O espectador não pode levar seu olhar para fora da trajetória traçada para ele, e acredita na história contada pela fábula. [...] O espectador tem a ilusão de ver a personagem real a sua frente. Tudo é feito para que ele se identifique. (PAVIS, 2007, p. 202-203).

Apesar de também produzir um efeito de ilusão no espectador, o Realismo se difere do Naturalismo. O primeiro:

Não se limita à produção de aparências, nem à cópia do real. Para ele, não se trata de fazer com que a realidade e sua representação coincidam, mas de fornecer uma imagem da fábula e da cena que permita ao espectador ter acesso à compreensão dos mecanismos sociais dessa realidade, graças à sua atividade simbólica e lúdica. [...] A cena tem que 'ex-primir', exteriorizar uma realidade contida a princípio em uma ideia; ela não fornece uma reprodução fotográfica ou uma quintessência do real. (PAVIS, 2007, p. 328).

Porém, ambos utilizam o efeito ilusionista da quarta parede ao tentar retratar a realidade no palco.

Por fim, afunilando os conceitos para o audiovisual, o naturalismo se esforça em direção à cópia fiel das aparências imediatas do mundo físico e à interpretação dos atores que busca uma reprodução fiel do comportamento humano, através de movimentos e reações "naturais" (XAVIER, 2005, p. 42). Já o realismo é a procura do que não é dado visivelmente de imediato, da fidelidade da "própria lógica da situação representada em suas relações não visíveis com o processo mais global a que ela pertence" (XAVIER, 2005, p. 55).

\section{Quebra da quarta parede}

Já o teatro contemporâneo "quebra deliberadamente a ilusão, (re)teatraliza a cena, ou força a participação do público" (PAVIS, 2007, p. 316, grifos do autor). E é com essa (re)teatralização que Vai Que Cola preenche sua narratividade através da quebra da quarta parede. Patrice Pavis $(2007$, p. 315) conceitua a quarta parede como "uma parede imaginária que separa o palco da plateia".

No teatro ilusionista (ou naturalista), o espectador assiste a uma ação que se supõe rolar independentemente dele, atrás de uma divisória translúcida. $\mathrm{Na}$ qualidade de voyer, o público é instado a observar as personagens, que agem 
sem levar em conta a platéia, como que protegidas por uma quarta parede (PAVIS, 2007, p. 315, grifos do autor).

Bertolt Brecht, influenciado por Piscator, que pretendera, em 1920, fazer do teatro um espaço de questionamento social na Alemanha, foi além. Para ele, era necessário o espectador ser retirado da passividade de obras com desfechos dogmáticos e da alienação produzida por qualquer ideologia representada. Sendo assim, apoiase em um princípio essencial, o Verfremdungseffekt, traduzido como o efeito de distanciamento, ou seja, a quebra da quarta parede (ROUBINE, 2003, p. 154).

Trata-se de colocar o objeto da representação à distância do espectador para que este experimente a sensação de sua estranheza. Para que o considere não mais como evidente, como 'natural', mas como problemático. Para que provoque sua reflexão crítica, [...] que permitam quebrar a ilusão teatral, levar de volta o espectador à consciência de si e à sensação de que aquilo que lhe é apresentado não é realidade, nem mesmo cópia perfeita, mas uma "representação", uma imagem insólita, problemática e desprovida de "natural" uma vez que admite sua natureza teatral (ROUBINE, 2003, p. 153).

Assim como o ator brechtiano, o ator de Vai Que Cola passa a ter um papel para além da interpretação ficcional em relação ao público. Só que o jogo na sitcom não é a conscientização política do público, mas, talvez, a produção de sensações na plateia do teatro e no telespectador através da transição da ficção para a não ficção, assim como através do caminho inverso (da não ficção para a fiç̧ão). Ou seja, buscam-se outros objetivos com a mesma ferramenta, os quais são definidos por dois diretores: César Rodrigues, que fica responsável pelas escolhas televisivas, e João Fonseca, que traz sua contribuição dos musicais.

\section{Exposição dos bastidores}

A interferência da voz do diretor de um seriado durante a transmissão de um episódio televisivo tradicional poderia soar estranha ainda nos dias de hoje, mas, quando utilizada no contexto da narrativa de Vai Que Cola, parece funcionar na estratégia de produzir o cômico.

O episódio "Por água abaixo" (MULTISHOW, 2013), de número 31, da 1a temporada, traz alguns minutos norteadores de apontamentos para esta análise. O fio condutor do enredo desse episódio é a falta de água na pensão. Na tentativa de se dar bem com a seca no Méier, Valdo enche garrafinhas para vender a preços exorbitantes aos próprios moradores. Mesmo com a ajuda da personagem Velna, interpretada por Fiorella Mattheis, seu esquema vai por água abaixo.

Em meio a essa trama ficcional, um dos diretores do programa, César Rodrigues, interfere no episódio quebrando o ilusionismo da narrativa ficcional. Esse momento é iniciado, nesse episódio em análise, quando a quebra da quarta parede é realizada pelo ator Paulo Gustavo. Ele se desfaz do personagem Valdo e fala irritado diretamente com a equipe do programa (olhando para lateral esquerda superior):

Paulo Gustavo: “Não entra uma 'piiiiii...' [censurado], aqui agora?".

Em plano aberto, aparecem a atriz Fiorella Mattheis e o ator Marcus Majella também despidos dos personagens. Logo em seguida, em primeiro plano, o ator confirma com o movimento vertical da cabeça: 
${ }^{4}$ Não necessariamente foi a resposta da plateia a esse específico acontecimento. Devido à edição, não se pode confirmar a sequência gravada dos planos.

${ }^{5}$ Vai Que Cola foi transmitido ao vivo apenas uma vez, na estreia da segunda temporada, com o episódio "Jeitinho brasileiro", dia 1으 de setembro de 2014.

${ }^{6}$ Informações sobre as duas gravações foram obtidas a partir da entrevista com o diretor César Rodrigues, concedida à autora por meio do aplicativo WhatsApp em 12 de setembro de 2015 .
No trecho acima, a atriz Catarina Abdala (Dona Jô) se esqueceu de entrar em cena, o que gerou um diálogo interno entre a equipe - obviamente, não se exclui a possibilidade de o diálogo com o diretor estar previamente elaborado no roteiro. O diretor não retirou esse evento da edição final do programa que foi ao ar, e, portanto, expõe também suas falas com os atores, completando a cena não ficcional:

\section{Diretor: “Ok?! Dona Jô, tá ok?!”.}

A atriz aparece, assustada, e confirma com a cabeça que está tudo certo. Em seguida:

Diretor: “Então deveria ter entrado!".

A atriz retorna ao fundo do cenário até não ser mais vista. Ao mesmo tempo, a plateia oferece aplausos eufóricos até aparecerem em primeiro plano. O fim da exposição de bastidores é concluído com o plano dos aplausos. É retomada, a partir de então, a história ficcional que havia sido interrompida, quando Catarina Abdala entra em cena com a máscara da personagem.

Mesmo que a pessoa física do diretor não apareça, o som da sua voz ao direcionar a cena proporciona um distanciamento da ficção, e em vez de se criar um estranhamento ou até uma certa rejeição por parte do telespectador com a quebra da ilusão naturalista, a edição do programa deixa a entender que o público responde com risadas. Para o telespectador, esse efeito é reforçado com o plano da plateia aplaudindo a cena retratada logo após a intervenção do diretor, induzindo ou reforçando o efeito positivo do erro de cena ${ }^{4}$.

Apesar de parecer, esse episódio não foi transmitido ao mesmo tempo em que foi captado. Mesmo que a imprevisibilidade do episódio possa convencer telespectadores de que o programa foi transmitido ao vivo sem muito planejamento, ele foi gravado. Vai que Cola é em quase sua totalidade gravado em um complexo ritual de captação de imagens ${ }^{5}$. Após os ensaios, duas gravações são realizadas no mesmo dia. Na primeira, que é feita sem a presença da plateia, são estabelecidos os valores mais qualitativos de um produto televisivo. É quando o diretor Rodrigues estabelece enquadramentos mais organizados, valores estéticos de movimento, a forma adequada de o ator falar o texto, e incorpora as experiências dos ensaios ao produto.

Já a segunda gravação é feita com a presença da plateia. Geralmente, ela dura em torno de uma hora, e dela são retirados aproximadamente 15 minutos, que contêm erros como problemas técnicos, giros errados do palco (o palco gira sobre seu próprio eixo) e interferência involuntária da luz. Os planos descartados ou trocados por imagens captadas na primeira gravação são retirados até cada episódio conter aproximadamente 45 minutos $^{6}$.

Entre as duas gravações, logo após a entrada da plateia no estúdio, acontece a captação de imagens da plateia. O público presente no palco, geralmente, é comandado por um comediante de stand up que provoca risos e gargalhadas. Na edição final do episódio, que é concluída em dias diferentes das gravações, são encaixadas essas reações em meio a momentos cômicos estratégicos que simulam uma reação direta da plateia à piada dos atores.

Mas como surgiu esse produto televisivo gravado duas vezes e posteriormente editado, que ainda apresenta algumas características típicas de um produto transmitido ao vivo? 
Segundo o diretor Rodrigues (2015), o canal Multishow foi dando liberdade para a exposição dos erros e pedindo para que a equipe se apropriasse deles, pois achava original e condizente com a imagem de Vai Que Cola. Sendo assim, o diretor incentiva a recuperação da cena por parte dos atores e, na montagem final, ele elege o que vai ser mais interessante para o bom andamento do espetáculo. A química produzida entre os comediantes que compõem o elenco é também apontada pelo diretor como fundamental para uma atmosfera instantânea, que desde o início foi potencializada nos primeiros roteiros escritos pelo criador da sitcom, Leandro Soares.

A exposição dos bastidores, que, muitas vezes, faz parte do programa, poderia ser chamada de "tempo morto", expressão que, para Machado (2003, p. 136), significa "momentos em que nada acontece no sentido narrativo tradicional, e a desalienação da sequência, que substitui os nexos dramáticos convencionais pelo trabalho modelador do acaso".

Vai Que Cola, porém, trabalha com uma narrativa maior, que engloba tanto o sentido narrativo tradicional (ficção) quanto o não tradicional (não ficção dentro de uma obra ficcional televisiva). Explicando melhor, a utilização da simulação do ao vivo possibilita a desalienação da sequência (não ficção - exposta no caso acima com a interferência do diretor) a favor de uma narrativa mais ampla. Sendo assim, o "tempo morto" se torna parte do produto. A atuação das duas (ficção e não ficção) faz com que o programa alcance sua proposta de script: o cômico.

Portanto, na cena aqui retratada, "morto" não seria o melhor termo aplicado. Torna-se provavelmente um "tempo vivo", podendo, em alguns casos, chegar até a alcançar o clímax do episódio para alguns telespectadores. Está aí uma das principais características do ao vivo: transformar um possível erro - um material descartável, pelo menos para a maioria das séries - em produto.

\section{Técnica do real}

Entretanto, a exploração intencional do erro (que se opõe ao realismo e ao naturalismo) como parte da narrativa ficcional parece pouco comum até a década de 90 na televisão. Ao contrário, com a criação do videotape, a TV aprimorou novos formatos, principalmente nos programas de ficção, evitando e camuflando erros para conquistar ainda mais o público. As séries americanas, por exemplo, alcançaram seu sucesso na tentativa de aproximar o telespectador da história vivida pelos personagens. Dois conceitos dessa trajetória realista são propostos por Cássio Starling Carlos (2006).

Antes de explicar esses dois conceitos do autor, faz-se aqui uma consideração importante. O conceito de realismo de Patrice Pavis (2007, p. 328), exposto no item 2 deste artigo, provavelmente não seria o mesmo utilizado por Cássio Starling Carlos para as séries americanas. Talvez, Pavis atribuiria o conceito de naturalismo ao sucesso das séries americanas, pois, conforme o significado do autor, o naturalismo fornece uma reprodução fotográfica ou uma quintessência do real. Sendo assim, quando Carlos (2006, p. 43) diz que as séries americanas se tornaram "no mais fiel espelho da sociedade", localizado ainda neste item, o conceito de naturalismo de Pavis parece se encaixar perfeitamente.

Retornando à discussão anterior, o primeiro conceito de Carlos se constrói na "opção preponderantemente realista [...] que torna mais rico e impactante o chamado 'storytelling'" (CARLOS, 2006, p. 42). Ele acontece na "proximidade com a 'realidade'", quando "as histórias narradas nas séries buscam no realismo de cena e na duração seus dois pontos de sustentação" (loc. cit.). O depoimento de John Wells, um dos produtores da série Plantão Médico, de título original Emergency Room (ER) (NBC, 1994-2009), exemplifica bem a posição de Carlos: "Não fizemos um único episódio sobre a morte da mãe do Dr. Benton. A morte 
dela durou onze episódios porque é assim que as coisas realmente acontecem" (CARLOS, 2006, p. 42).

Segundo o mesmo crítico, uma segunda opção realista justifica ainda melhor a fama dos americanos:

O realismo mais forte e mais determinante para as séries terem se tornado fenômenos narrativos tão sofisticados está no fato de os criadores e roteiristas, há pelo menos uma década [até 2006, quando o livro foi escrito], terem-nas transformado no mais fiel espelho de sociedade hoje disponível na cultura de massas (Ibid., p. 43).

Entretanto, os dois efeitos de realismo de Carlos não contemplam a capacidade de Vai Que Cola alcançar seu público. Somente um terceiro conceito, proposto por Carlón (2012), parece justificar a capacidade da sitcom de retirar risos do telespectador por causa de um suposto erro da equipe do programa: a busca de um realismo através da técnica do real.

A técnica do real é a técnica da transmissão direta televisiva. Sendo assim:

a tomada direta é [...], antes de mais nada, um dispositivo ótico capaz de registrar o comportamento social de modo singular, [...] que se caracteriza por colocar esse comportamento simultaneamente ao alcance de todos [...] e assim ocupar no seu discurso, com a dimensão técnica que garante seu caráter realista, um lugar ainda maior do que no discurso cinematográfico (Ibid., p. 16).

A utilização da estratégia da transmissão direta em Vai Que Cola favorece a presença dos bastidores na simulação ao vivo, garantindo o terceiro caráter realista proposto por Carlón. Esse é um discurso da técnica do real que aproxima o telespectador da sitcom, como será discutido no próximo item deste artigo.

\section{Teatro como técnica do real}

Segundo Carlón (2012, p. 37), quando um veículo de comunicação realiza uma transmissão direta de uma fiç̧ão, é necessário comparar o produto resultante ao teatro. Não por acaso, o objeto de estudo foi realizado em um palco teatral. Talvez esteja aí um produto híbrido (mistura de TV e teatro) que justifique a simulação do ao vivo. Para tentar alcançar esse objetivo, ambos os diretores levam em Vai Que Cola a atmosfera teatral para a televisão.

O diretor Rodrigues (2015) atribui como contribuição determinante ao sucesso do programa o show televisivo proporcionado pelo teatro. Para ele, o teatro "entra nessa comunicação, naquele espaço, como um show" (RODRIGUES, 2015). Porém, deixa claro que é um produto televisivo, e não um teatro gravado. Segundo o diretor, se ele estivesse gravando um teatro, utilizaria apenas uma câmera parada em plano aberto para captar a atuação sobre o palco. Ao contrário, o processo de gravação é complexo. São utilizadas no mínimo sete câmeras que captam diferentes enquadramentos durante as duas gravações. O ritmo dos cortes dados pela edição do programa denuncia o grande número de enquadramentos

${ }^{7} \mathrm{O}$ número de câmeras foi testemunhado pela autora na visita da gravação do programa, em 2 de junho de 2015, e confirmada, nesse mesmo dia, pelo depoimento do cameraman, Julio Mirancos, responsável pela câmera de número dois do programa, posicionada na segunda fileira da plateia. fornecido pelas variadas câmeras estrategicamente posicionadas?

Essa complexidade e o hibridismo são reforçados pelo diretor Fonseca (2015): "tem hora que a gente está fazendo para a televisão, e tem hora que a gente está fazendo para a plateia dali [presente na segunda gravação] e para a televisão [ao mesmo tempo]".

O ao vivo transmitido a partir do formato teatral já foi anteriormente experimentado com sucesso em sitcoms brasileiras, tanto por necessidade 
tecnológica, que foi o caso de Família Trapo (1967-1971) da Rede Record de Televisão, quanto uma simulação trazida por Sai de Baixo (1996-2002) da Rede Globo de Televisão. Segundo registros da Rede Record, a sitcom foi criada às pressas devido ao incêndio de 1966, quando vários videotapes de programas gravados que iriam ser transmitidos pela programação da emissora foram queimados (YES; BOTTINI; CHAHESTIAN, 2003). Já a sitcom da Rede Globo foi criada no propósito de simular o ao vivo provocando o telespectador (FILHO, 2003, p. 47), assim como a atual sitcom do Multishow.

A fiç̧ão televisiva brasileira ocupa boa parte do tempo de produção do ainda onipresente aparelho de TV (PALLOTTINI, 2012). Para Renata Pallottini:

o programa televisivo de ficção é a história, mais ou menos longa, mais ou menos fracionada, inventada por um ou mais autores, representada por atores, que se transmite com linguagem e recursos de TV, para contar uma fábula, um enredo, como em outros tempos se fazia só no teatro e depois passou a se fazer também no cinema (PALLOTTINI, 2012, p. 24).

Para aprofundar na transmissão do real da ficção Vai Que Cola, ignora-se aqui, pelo menos por enquanto, o hibridismo de planos (cinema/televisão) sobrepostos pela dissolução das fronteiras formais e materiais dos suportes e linguagens levantada por Machado (2003). Ignora-se também a diferença de definição e qualidade de imagem dentro dos próprios produtos televisivos citados por Pallottini (2012). O foco será a técnica do real e sua relação com a representação teatral.

Segundo Renata Pallottini (Ibid., p. 24), "a ficção de TV utilizou da experiência desses dois veículos, o teatro e o cinema". Na sitcom, é possível identificar elementos da representação teatral. Aproveitam-se as palavras do diretor Fonseca para apontar algumas características teatrais em Vai Que Cola: a presença da plateia e a ação corporal.

A relação com o público é o teatro, tem a plateia na frente [do palco]. A plateia pode levar o personagem e levar o espetáculo. A reação da plateia chega neles imediatamente. Eles não vão saber meses depois nas ruas [fazendo referência às telenovelas, por exemplo]. $E$ isso acaba tendo uma troca. [A ação corporal] acaba sendo um pouco maior também. Eles estão soltos. Então, corporalmente é muito grande. As expressões e as brincadeiras são teatrais (FONSECA, 2015).

Essa representação teatral é, para Christian Metz (1980), uma representação real.

A representação, no teatro, é inteiramente real. [...] Deste modo, a ficção teatral é mais sentida como um conjunto de comportamentos reais activamente orientados para a evocação do real - trata-se apenas de uma "dosagem" diferente, de uma diferença de economia, melhor dizendo, mas é precisamente por isso que é importante. (METZ, 1980, p. 79, grifo meu).

O teatro em Vai Que Cola é "transmitido com linguagens e recursos de TV para contar uma fábula" (PALLOTTINI, 2012, p. 24). Entretanto, além dessa ficção produzida, a representação real de Metz parece produzir também a não ficção. Essa não ficção surge na sitcom através da quebra da quarta parede pelos atores, que produz a sensação de realidade, distancia o telespectador da ficção. Sendo assim, o ator Paulo Gustavo aproveita o fato de que "o material usado para figurar a diegese no teatro são as pessoas reais efetivamente presentes no espetáculo" (METZ, 1983b, p. 422) e retira a máscara do personagem Valdo no palco da sitcom.

No grande teatro, 
${ }^{8}$ Já é possível testemunhar fragmentos e obras cinematográficas ao vivo como, por exemplo, o longa-metragem Fluidos do diretor Alexandre Carvalho, apresentado pela primeira vez no Centro Cultural São Paulo em 16 de maio de 2009. Mas a TV, por enquanto, é veículo quase único.

${ }^{9}$ Mário Carlón conceitua a tese da existência da transmissão em tomada direta televisiva como: "sabemos que são reais, que estão fazendo alguma coisa neste exato momento" (CARLÓN, 2012, p. 62, grifo do autor).
O ator e o espectador fazem-se presentes um ao outro, em que o desempenho (desempenho do comediante, desempenho do público) é também uma partilha lúdica dos papéis (das caracterizações), um consentimento duplo e ativamente cúmplice, uma cerimônia algo cívica sempre, a empenhar mais que o homem privado: uma festividade (METZ, 1983a, p. 406).

Quando Paulo Gustavo quebra a quarta parede, pode-se propor a troca de uma "partilha lúdica" citada por Metz (1983a) por uma "partilha de realidade". É como se tanto o ator quanto o telespectador se despissem da caracterização de seus respectivos papéis propostos pela diegese e fossem cúmplices de um mesmo estado presente - pessoas no mundo real - ao dividirem o erro de gravação ou de transmissão ao vivo. Ambos, pois, participam da gravação do programa como pessoas na vida real, como eles mesmos, naquele instante.

Nessa diferença entre ficção e não ficção real do teatro, a obra do Multishow busca uma unidade, certo equilíbrio. Equilíbrio esse, aparentemente, até agora só possível de ser alcançado no audiovisual através da televisão. Deve-se isso à transmissão direta, ao ao vivo ${ }^{8}$.

\section{O espelho}

De acordo com Carlón (2012, p. 51, grifo do autor), "a representação da transmissão direta televisiva é menos real do que a das práticas sociais, mas mais real do que a da gravação (cinema e televisão gravados)". Essa técnica de transmissão, para o autor, tem um dispositivo que fortalece a "tese da existência" (Ibid., p. 62, grifo do autor), seja diante de um acontecimento não ficcional ou de uma obra de ficção?.

Na tentativa de ilustrar o dispositivo que potencializa a tese da existência, Carlón compara a transmissão direta televisiva ao espelho:

Suponhamos que nos encontramos sentados em uma poltrona, e que na parede que está diante de nós, mas não exatamente situado diante de nós, mas em ângulo oblíquo, há um espelho. Suponhamos também que em outra parede, que se vê refletida no espelho, há uma janela que dá para um jardim, e que da nossa posição não podemos ver nem o jardim nem a janela. Mas suponhamos, assim mesmo, que se olharmos o espelho, nele podemos ver a janela, e através dela o jardim. Suponhamos que no jardim está passeando um animal doméstico, um gatinho. No espelho podemos ver cada movimento que ele faz. (Ibid., p. 51).

O espelho funciona como um dispositivo em tomada direta sem delay, afirma. “Acreditamos nele?", pergunta Carlón ao questionar sobre o espelho. Ele mesmo responde: "Sim, plenamente, porque o espelho, tal como o conhecemos, não somente funciona em tomada direta, mas, além disso, é indicial e seu registro é automático: a imagem que vemos surge [...] da ontologia do objeto" (Ibid., p. 51, grifos do autor). Ainda não satisfeito, o autor esclarece por que consideramos real a imagem refletida no espelho, que é um duplo do verdadeiro gatinho:

Porque a enunciação do espelho, como dispositivo, é técnica, maquinal e automática, dado que evidentemente não há a intervenção de nenhum operador (não há ninguém a manipulando, a única presença humana que intervém é a nossa). [...] O que nos é permitido com esta experiência? (Ibid., p. 51-52)

Com essa pergunta, amplia-se nosso tema em debate: o que nos é permitido com a experiência de simulação do ao vivo em Vai Que Cola? Pode-se arriscar, por enquanto, uma resposta com as mesmas palavras de Carlón (2012, p. 52, grifos 
${ }^{10}$ É importante relembrar que Vai Que Cola é um produto, em sua maioria, gravado, e foi transmitido ao vivo apenas uma vez, na estreia da segunda temporada, com o episódio "Jeitinho brasileiro", dia 1 ㅇ de setembro de 2014

\footnotetext{
${ }^{11}$ Entrevista concedida à autora no Riocentro, no Rio de Janeiro, em 4 de junho de 2015.
}

do autor): "Antes de mais nada, ver em tempo real os movimentos de um real que está fora do nosso alcance, em outro espaço". Assim, em primeiro lugar, "ver em tempo real" significa que o telespectador da sitcom contempla a programação do canal assistindo-a pela TV. Em segundo, "os movimentos de um real" se fazem presentes quando o diretor do programa dialoga diretamente com a atriz Catarina Abdala (não com a personagem). E, por fim, "que está fora do nosso alcance, em outro espaço": a gravação acontece no Rio de Janeiro, enquanto o espectador televisivo assiste em casa $^{10}$.

\section{O telespectador ativo}

Carlón (2012, p. 17) questiona se "a transmissão direta televisiva, além de ser uma técnica e um dispositivo, é também uma linguagem". Sem a intenção de afirmar ou negar essa possibilidade, por enquanto, pode-se dizer que Vai Que Cola estaria tentando utilizar dessa estratégia do ao vivo para buscar a realidade do processo de produção, da técnica do real, do que realmente está acontecendo por trás das câmeras no momento de gravação (e não da ficção).

O depoimento do criador da sitcom, Leandro Soares, parece corroborar essa hipótese:

O Vai Que Cola se expõe em tudo. O cenário se expõe. Você vê o cenário girar, você vê as trocas [de cenário]. Ninguém está aqui querendo fingir que não é um cenário. $O$ pacto é diferente. $O$ pacto com o espectador é: vamos rir de alguma coisa que a gente sabe que é. Não é um realismo ilusionista. É uma farsa. $\mathrm{O}$ cenário se expõe, como o texto se expõe. [...] Às vezes está [no roteiro] e às vezes eles [os atores] colocam. Você não tem como dizer. Tem piadas do roteiro falando mal do próprio roteiro, que estão escritas no roteiro. (SOARES, 2015). ${ }^{11}$

Sendo assim, o programa cria a oportunidade de mobilizar o telespectador em uma estratégia de linguagem própria, simulando o tempo presente.

A operação em tempo presente pode, esporadicamente, fazer acontecer alguns momentos de verdade com uma intensidade inatingível em qualquer outro meio de comunicação, o que não deixa de ser surpreendente numa mídia tão vigiada e controlada como a televisão. (MACHADO, 2003, p. 138).

A busca dessa intensidade inatingível não se compara à morte de Ayrton Senna ou à votação, pelo Congresso Nacional, da cassação de Fernando Collor de Mello, pois ambas geraram uma paralisação nacional (Ibid., p. 139). Mas é comparável, sim, a uma produção de sentido intenso no âmbito da produção televisiva ficcional.

"A transmissão ao vivo talvez seja, dentre todas as possibilidades de televisão, aquela que marca mais profundamente a experiência desse meio" Ibid., p. 129). Ao negar Pierre Bourdieu, que diz que a televisão não favorece o pensamento, e ao negar também a ideia de televisão nociva de Paul Virilio, Machado afirma que

a televisão não se resume em uma única emissão: ela consiste num fluxo ininterrupto de imagens e sons, que progride diariamente diante dos nossos olhos e ouvidos, perfazendo, portanto, um processo, ao longo do qual o espectador pode formar uma opinião. (Ibid., p. 129).

O autor completa que "a reflexão do telespectador, por se dar ao vivo, ou seja, num processo que ainda está em andamento, pode tomar a forma de ação política" e "resultar em mobilização", assim como "torna ainda possível uma intervenção" (Ibid., p. 129). 
Colocando a mobilização no contexto de Vai Que Cola, observa-se que a transmissão direta pode trazer o telespectador mais perto da narrativa. Nessa aproximação está uma tentativa, mesmo que tímida, de repassar ao telespectador a sua capacidade de se envolver no processo de produção do programa, diferentemente do realismo das séries americanas citado por Carlos (2006). Segundo Carlón (2012, p. 38), a "contemplação televisiva não pode ser senão uma prática ativa, mobilizadora, diante da contemplação [...] de uma notável quantidade e diversidade de saberes por parte de seus sujeitos telespectadores".

Carlón aponta ainda, no mínimo, dois níveis de intervenção do sujeito espectador nessa mobilização de caráter técnico e social. No primeiro, assume uma posição como espectador. O segundo é o processamento pelo espectador das mudanças que podem ser produzidas durante uma mesma emissão, "coisa que acontece, por exemplo, com a distância entre ficção e não ficção, que tanto na gravação como na transmissão direta costuma ser muito curta nas emissões televisivas (mais do que no cinema)" (loc. cit., grifo do autor).

O telespectador de Vai Que Cola parece ter a oportunidade de experimentar ambos os níveis de intervenção. O primeiro acontece quando o telespectador assume sua posição e se conscientiza do seu papel como espectador, ao ser distanciado pela quebra da quarta parede proposta no episódio "Por água abaixo" pelos atores Paulo Gustavo, Catariana Abdala, Marcus Majella e Fiorella Mattheis.

O segundo nível acontece quando a sitcom exacerba a passagem da ficção para uma suposta não ficção. A interferência do diretor (presente ou não no roteiro), juntamente com a reação da plateia, durante quase vinte segundos do episódio, fornece ao telespectador tempo suficiente para processar a mudança. A exposição do bastidor quando o diretor direciona a atriz Catarina Abdala, e não a personagem Dona Jô, parece mais uma tentativa de fazer que o telespectador tenha um sentimento de uma participação ativa na produção do programa, naquele momento (na ação dos diretores e dos atores). Essa é uma suposta simulação que pode ser provocada por meio da função ilusionista da construção audiovisual $^{12}$.

${ }^{12}$ No caso, a função ilusionista da construção audiovisual propõe a ideia de compartilhamento instantâneo do processo de produção com o telespectador, por parte da equipe técnica. Esse compartilhamento pode ficar restrito a uma ilusão, uma vez que a série foi gravada antes do telespectador assistir em casa.

\footnotetext{
${ }^{13}$ No original: "It is for this reason that 'traditional' sitcom is filmed in front of a studio audience. [...] This audience is signalled to the viewers at home through the laugh track, which, as the 'electronic substitute for collective experience' (Medhurst and Tuck 1982, p. 45), helps align domestic viewers with those who were present at the live recording".
}

Antes de prosseguir o raciocínio, é interessante observar que o telespectador não abandona sua posição de sujeito-observador. A participação ativa do telespectador é apenas sensorial e não efetiva, pois ele não interfere na construção da sitcom ao mesmo tempo em que assiste em casa. Essa interferência fica restrita à plateia presente na gravação do programa. Como já citado pelo diretor Fonseca (2015), a plateia tem a capacidade de conduzir um espetáculo e, consequentemente, o programa Vai Que Cola. Além disso, ela passa a impressão de coletividade, como apontado por Brett Mills (2009, p. 39) em The Sitcom. Por isso, a plateia tem uma função fundamental na sitcom e em produtos cômicos. Para simbolizar a plateia presente no estúdio, a sitcom tradicional americana faz uso da claque - risada eletrônica colocada durante e depois de uma piada:

\footnotetext{
É por isso que a sitcom "tradicional" é gravada em frente de uma plateia no estúdio. [...] Através da claque, essa plateia é sinalizada para o espectador de casa e, enquanto "substituto eletrônico para a experiência coletiva" (MEDHURST; TUCK, 1982, p.45), ajuda a alinhar o espectador doméstico com os presentes na gravação ao vivo ${ }^{13}$. (MILLS, 2009, p. 16, tradução minha).
}

Em Vai Que Cola, a claque é composta com a risada da própria plateia da sitcom. A risada da plateia é captada antes (na introdução feita por um comediante de stand-up) e durante a gravação do episódio. Além da claque, a sitcom também conta com imagens da reação da plateia como estímulo à coletividade. A exibição desse plano é, para o criador da sitcom, Leandro Soares (2015), uma característica 
${ }^{14}$ Informação obtida a partir da entrevista com o criador de Vai Que Cola, Leandro Soares, concedida à autora no Riocentro, RJ, em 4 de junho de 2015.

\footnotetext{
${ }^{15}$ Informação obtida a partir da entrevista com o diretor César Rodrigues, concedida à autora por meio do aplicativo Whatsapp em 12 de setembro de 2015.
}

tipicamente brasileira que funciona. Ele complementa que as séries americanas se utilizam da claque, mas não da imagem da plateia ${ }^{14}$.

O uso de ambas foi planejado desde o início para que também compusessem a dramaturgia de Vai Que Cola. Quando o programa ainda não fazia sucesso, a plateia era convidada e contratada. A recomendação aos produtores de plateia era reunir grupos de família: namorados, mãe, pai e filhos, sempre que possível. O diretor Rodrigues acreditava na química gerada por essa relação, com a função de criar uma atmosfera de intimidade, pois o programa era "para ser visto em família, com quem a gente gosta" (RODRIGUES, 2015). O objetivo era fazer que a plateia representasse o telespectador que assistisse ao programa de casa ${ }^{15}$.

Após o feedback bem sucedido do público ao fim das duas primeiras temporadas, o diretor afirma que a comunicação da plateia com o espetáculo Vai Que Cola acabou se concretizando

porque quando você vê aquele grupo reunido ao cortar para a plateia, você percebe que tem uma relação, que tem um riso que está ali, que está associado a uma segurança. Esse riso, para mim, é fundamental quando ele nasce e [...] quando está terminando, [...] mais do que quando ele está no meio. Pois é quando vem espontaneamente o movimento do riso. $E$ isso faz parte da dramaturgia que eu pensei para esse programa, desde o primeiro momento. [...] E eu acho que o cara em casa, na minha cabeça, quando vê isso, fala: "Eu queria estar ali com quem eu gosto.", "Eu quero assistir esse programa.". Mesmo que intuitivamente, mesmo que sensorialmente. Eu acho que isso tudo é muito importante. [...] Nessa hora, o show fica pra todo mundo. (RODRIGUES, 2015).

Retornando à possibilidade de um telespectador mais atuante em Vai Que Cola, propõe-se, como já falado, apenas uma simulação de uma participação ativa na produção da sitcom. Sugere-se o estímulo do público de casa ao se espelhar na plateia presente na gravação, mesmo que inconscientemente.

O realismo de Carlos utilizado nas séries americanas se torna completamente ausente nesse instante em Vai Que Cola, visto que o que mais atrai o telespectador na sitcom do Multishow não é mais a narrativa fiel ao espelho da sociedade (CARLOS, 2006, p. 43). Arriscando mais longe, a proposta pode ser a busca de ultrapassar esse espelho social de Carlos (2006) e ultrapassar também o limite do ao vivo proposto por Machado (2003, p. 126). A tentativa é a de ter um telespectador mais ativo. É a de provocar nele uma sensação de também fazer parte do staff da produção de Vai Que Cola. Segundo Rodrigues (2015), quando essa história [ficcional] erra, ou quando o ator se diverte com o outro, ele troca com o espectador, tanto o de casa quanto aquele da plateia.

Sem dúvida, para afirmar cientificamente se essa sensação de staff é efetivada no telespectador da sitcom, precisa-se de um estudo de recepção. Como esse não é o objetivo do artigo, levanta-se, neste momento, uma possibilidade de causa para o sucesso de público do produto. As teorias sobre o ao vivo de Carlón e Machado parecem somar às estratégias dos diretores Rodrigues e Fonseca e corroboram a opinião deste artigo.

Ao longo de sua trajetória, Vai Que Cola formatou uma comunicação livre e espontânea que normalmente os programas tradicionais acabam não abordando. De acordo com o diretor Rodrigues, tal formato seria quase um reality: "Eu acho que esse momento em que todo mundo quer fazer parte do show, alegra e envolve. E acabou sendo uma marca do programa" (RODRIGUES, 2015).

A sensação de coletividade do show é promovida pela transmissão direta ou por sua simulação, juntamente com a plateia. Por isso, afirma Machado que o ao vivo "requer um pensamento vivo e em ação" (MACHADO, 2012, p. 130, grifo do autor). 
Portanto, concluindo metaforicamente, a utilização de elementos do ao vivo na sitcom é a peça chave para fornecer ao telespectador a sensação de sair da poltrona da TV e ir para a plateia do teatro (através da reação da plateia em planos televisivos com simulação do ao vivo). E, ainda, a sensação de ir da poltrona do teatro para cima do palco (quando acontece a quebra da quarta parede por parte dos atores). Não parando por aí, uma terceira sensação pode ser produzida, a de ir para trás das cortinas e fazer parte dos bastidores (ao dividir a instrução do diretor do programa aos atores).

Acentua-se assim ainda mais o grau de realidade, trazendo o telespectador para o tempo presente do programa televisivo e fortalecendo a "tese da existência" de Carlón (2012, p. 52, grifo do autor). Vai Que Cola fornece ao telespectador uma simulação de participação, participação não só da história ficcional, mas do conjunto: da ficção e do processo de gravação de Vai Que Cola. Ele se torna, sensorialmente, um telespectador ativo.

\section{Conclusão}

Ao ser questionado no programa Roda Viva, da TV Cultura de São Paulo, se hoje o consumidor é visto como elemento passivo, alienado e dominado, o filósofo da hipermodernidade Gilles Lipovetsky responde:

Não. Essa era a visão dominante nos anos 60. O consumidor era manipulado pelas vitrines, supermercados, pela publicidade, é claro, como se o consumidor fosse um objeto. Havia vários tipos de mensagens que o alienavam. Era a alienação pelos objetos. Eu acho que era uma perspectiva ilusória, que não via como o mundo dos objetos desengajava, de certa forma, os indivíduos. E como sabemos hoje, a informação dá todos os tipos de ferramenta para a reflexão, para o melhor e para o pior. Porque hoje o consumidor, longe de ser essa pessoa alienada, é uma pessoa consciente. Ele sabe o que come, se isto é bom, se não é. Se for tomar sol, que creme deve passar, que atividade deve fazer para ficar saudável. Desde que o modelo da saúde se tornou esse estilo saudável, temos um outro consumidor, que eu chamo de hiperconsumidor ou um consumidor reflexivo e que não tem nada a ver com o modelo de alienação que existia nos anos 60. (LIPOVETSKY, 2004).

Coincidentemente ou não, o consumidor dos anos 60 foi o que testemunhou o fim do teleteatro e a criação de programas televisivos gravados graças à invenção do VT. Já o "hiperconsumidor" brasileiro de Lipovetsky está testemunhando a construção de programas de ficção com o retorno de características do teleteatro, captadas por câmeras com estratégias de linguagem televisiva com mais de 60 anos de experiência e várias influências estrangeiras, com possibilidade de pós-produção, tudo em um produto híbrido televisivo que simula a transmissão ao vivo.

Esse novo consumidor, influenciado pela geração denominada pelos americanos de Millennials (Geração Y) - para se referir aos que nasceram entre 1980 e 2000 -

${ }^{16}$ Para a antropóloga Valéria Brandini, a sociedade como um todo é multitarefa hoje em dia, até os mais velhos. são tidos como multitarefa ${ }^{16}$. Para a antropóloga Valéria Brandini (2013), é comum começarem uma tarefa com um objetivo e terminarem com um fim bem diferente do proposto. Ainda segundo ela, eles mudam de ideia na velocidade do twitter e do instagram. Seu estilo de vida é quase um reality show nas redes sociais. São imprevisíveis, assim como a transmissão ao vivo, continua a antropóloga.

Acompanhando essa nova geração, Vai Que Cola busca fazer do "tempo da enunciação como um tempo presente ao espectador" (MACHADO, 2003, p. 15). Sendo assim, o hibridismo (ficção, não ficção; técnicas e bastidores escondidos e expostos; erros transmitidos durante o programa e outros retirados; cenários que ocupam um mesmo espaço perante o público proporcionado pelo palco giratório; formato televisivo e teatral; entre outros) forma uma grande narrativa televisiva 
ainda experimental (apesar de já termos produções anteriores e contemporâneas), para além do texto decorado.

É importante destacar que a proposta da não ficção não supera a importância da narrativa ficcional na sitcom - não se intentou demonstrar alguma hierarquização. A utilização de ambas gera sensações específicas no telespectador, ainda que a ficção domine maior tempo dos episódios.

A partir de tantas possibilidades, não há como não concordar com Carlón:

O seu reconhecimento do "caráter imprevisível" da transmissão direta, constitui uma exceção significativa. Por isso, faço notar que o lugar dessa técnica do real, que é simultaneamente uma linguagem e um dispositivo específico no sistema das linguagens contemporâneas, constitui ainda uma incógnita. Uma incógnita que a meu ver, não começará a nos ser revelada até que não tenhamos proposições sólidas e minimamente consensuais acerca do assunto (CARLÓN, 2012, p. 37, grifo do autor).

Ainda há muito para ser discutido e revisto sobre a imprevisibilidade de fazer teatro para a televisão, ou fazer televisão no teatro, ao vivo ou simulado. Sem a pretensão de colocar um ponto final na indagação dessa complexidade, seja ela fruto de uma modernidade tardia ou de um simples pastiche pós-moderno de Frederic Jameson (CONNOR, 1993), pretendeu-se, apenas, levantar algumas possibilidades sobre a técnica do real e seu telespectador (CARLÓN, 2012) em Vai Que Cola.

\section{Referências Bibliográficas}

AMORIM, A. C. B. et al. Rede Record: 45 anos de história. São Paulo: Design, 1999.

BRANDINI, V. Millenials brasileiros e papel da tecnologia na vida dos jovens. 26 set. 2013. Disponível em: <http://valeriabrandini.blogspot.com.br/2013/09/ valeria-brandini-fala-do-papel-da.html>. Acesso em: 20 ago. 2014.

CARLÓN, M. Do cinematógrafo ao televisivo: metatelevisão, linguagem e temporalidade. Tradução de Cecilia Prada. São Leopoldo: UNISINOS, 2012.

CARLOS, C. S. Em tempo real: Lost, 24 Horas, Sex and the City e o impacto das novas séries de TV. São Paulo: Alameda, 2006.

CONNOR, S. Cultura pós-moderna. São Paulo: Loyola, 1993.

DIDEROT, D. Discurso sobre a poesia dramática. Tradução, organização, apresentação e notas de Frank de Mattos. 2. ed. São Paulo: Cosac Naify, 2005.

FILHO, D. O circo eletrônico: fazendo TV no Brasil. Rio de Janeiro: Jorge Zahar, 2003.

FONSECA, J. Entrevista concedida a Ana Márcia Andrade. Ana Márcia Andrade. Rio de Janeiro: Riocentro, 4 jun. 2015.

LIPOVETSKY, G. Programa roda viva. Memória Roda Viva. 16 dez. 2004. Disponível em: <http://www.rodaviva.fapesp.br/materia/567/entrevistados/gilles_ lipovetsky_2004.html>. Acesso em: 06 jun. 2014.

MACHADO, A. A televisão levada a sério. 3. ed. São Paulo: Senac São Paulo, 2003. 
MATTOS, S. 1948 - Um perfil da TV brasileira: 40 anos de história - 1950/1990. Salvador: Associação Brasileira de Agências de Propaganda, 1990.

MEMÓRIA GLOBO. Sai de Baixo. Disponível em: <http://memoriaglobo.globo. $\mathrm{com} /$ programas/entretenimento/humor/sai-de-baixo/producao.htm>. Acesso em: 20 jun. 2014.

METZ, C. História do discurso: notas sobre dois voyeurismos. In: XAVIER, I. (Org.). A experiência do cinema: antologia. 3. ed. Rio de Janeiro: Graal; Embrafilme, 1983a. p. 403-410.

O dispositivo cinematográfico como instituição social entrevista com Christian Metz. In: XAVIER, I. (org.). A experiência do cinema: antologia. 3. ed. Rio de Janeiro: Graal; Embrafilme, 1983b. p. 411-434.

. O significante imaginário: psicanálise e cinema. Tradução de António Durão. Direção de Salvato Teles de Menezes. Lisboa: Horizonte, 1980. (Coleção Horizonte de Cinema)

MILLS, B. The sitcom. Edinburgh: Edinburgh University Press, 2009.

MULTISHOW. Vai Que Cola. 2013. Disponível em: <http://multishow.globo.com/ diario-de-gravacao/platb/2013/06/19/paulo-gustavo-fala-sobre-relacao-comdiretores-de-vai-que-cola/>. Acesso em: 5 dez. 2013.

PALLOTTINI, R. Dramaturgia de televisão. 2. ed. São Paulo: Perspectiva, 2012.

PAVIS, P. Dicionário de teatro. 3. ed. São Paulo: Perspectiva, 2007.

POR ÁGUA abaixo. Vai Que Cola. 1a Temporada, episódio 31. Diretor: César Rodrigues e João Fonseca. Produtor: Conspiração Filmes. Rio de Janeiro: Multishow, 19 agosto 2013. Série. Disponível em: <http://multishow.globo.com/ programas/vai-que-cola/episodios/773.htm>. Acesso em: 19 jun. 2014.

RODRIGUES, C. Entrevista concedida a Ana Márcia Andrade. Ana Márcia Andrade. Entrevista concedida por WhatsApp, 12 set. 2015.

ROUBINE, J-J. Introdução às grandes teorias do teatro. Rio de Janeiro: Jorge Zahar, 2003.

SILVA, F. L. P. (Coord.). O Teleteatro Paulista nas décadas de 50 e 60. (Cadernos, 4). São Paulo: Secretaria Municipal de Cultura, Departamento de Informação e Documentação Artísticas, Centro de Documentação e Informação sobre Arte Brasileira Contemporânea, 1981.

SOARES, L. Entrevista concedida a Ana Márcia Andrade. Rio de Janeiro: Riocentro, 4 jun. 2015.

XAVIER, I. O discurso cinematográfico: a opacidade e a transferência. 3. ed. São Paulo: Paz e Terra, 2005.

YES, P.; BOTTINI, M.; CHAHESTIAN, A. 50 Anos Record. São Paulo: Referência, 2003. 